\title{
The determinants of the choice of treatment of pregnant women in Cameroon
}

\author{
Saturnin Bertrand Nguenda Anya* and Atanase Yene
}

\begin{abstract}
This paper seeks to identify the determinants of the choice of treatment of pregnant women in Cameroon. Theoretically, the methodology is based on a discrete choice model with random utility. Empirically, the econometric specification is a Nested Multinomial Logit Model. The data used comes from the Demographic Health Survey (DHS) organized in 2011 by the National Institute of Statistics. The results reveal that uneducated women or those having only a primary education prefer to meet the traditional midwives than seek modern maternal health services. Moreover, the absence of a paid job for the pregnant woman, the large size of the household, Islamic or animist religion, poverty, high costs of healthcare and transportation are constraints which make the pregnant woman to prefer the services of traditional midwives to modern services of maternal health. The use of modern healthcare services by pregnant women in Cameroon can therefore be improved by at least two means: firstly, by improving on the level of education of women and economically empowering them. Secondly, in a context where the costs of healthcare services are paid directly by the pregnant women themselves or by their families, it is important to put in place health insurance schemes in order to guarantee proper follow-up of pregnant women until delivery as well as taking care of complicated cases.
\end{abstract}

Keywords: Choice of treatment, Pregnant women, Maternal health, Nested multinomial logit model

\section{Background}

The health services received by a mother during pregnancy, at birth and immediately after delivery are not only important for her health and survival but also for those of the child. Health is an element of human capital, as well as education and nutrition. In fact, [1] defines human capital as a set of cognitive, physical, nutritional, and biological aptitudes which reinforce human capacities. Human capital has two main components: education and health. The application of the concept of human capital to health was initially developed by [1], followed by [2] who develops the concept of healthcapital. In fact, the notion of health-capital considers health as a perishable good whose stock must be maintained by investments in health. According to the healthcapital model, individuals receive a stock of health-capital at birth, which depreciates with time but can be increased

* Correspondence: nguenduz_144@yahoo.fr

Faculty of Economics and Applied Management, University of Douala, Douala, Cameroon

(c) The Author(s). 2016 Open Access This article is distributed under the terms of the Creative Commons Attribution 4.0 International License (http://creativecommons.org/licenses/by/4.0/), which permits unrestricted use, distribution, and reproduction in any medium, provided you give appropriate credit to the original author(s) and the source, provide a link to the Creative Commons license, and indicate if changes were made. through investment; death occurs when the stock of capital falls below a given threshold. For this reason, health services are considered as a necessary input for the production of the optimal stock of health-capital [3]. From this point of view, the non consumption or low consumption of maternal health services constitutes an obstacle to health-capital, hence human capital. Also, with the extension of consumer theory by [4], utility no longer depends only on the quantity of goods but also on the characteristics of these goods. The utility the pregnant woman derives from health services thus depends on the characteristics of the health services. Following this approach, women arbitrate between the alternative sources of treatment according to the characteristics of the maternal health services. In this context, lack of courtesy by the personnel, humiliating and mocking remarks made towards certain women; long queues and sometimes hurried consultations, for example, create a disutility and prevent the recourse to modern health services [5]. \\ 吾 Springer Open}


There is an abundant literature on the determinants of the usage of maternity services in low or middle income countries. These studies focus on the determinants of the usage of maternal health services [6-9], or on the frequency of utilisation of these services [10-12]. Others focus on the relationship that exists between the utilization of maternal health services and factors like the place of residence [13], the level of education of the mother [8, 14], the wealth index of the household $[8,15]$, the income of the mother and her ethnic group [14]. However, this empirical literature does not give enough information on the determinants of the choice of treatment of expecting mothers in an environment where a variety of modern health services coexist with those of traditional midwives.

In Cameroon, [16] find that the proportion of the pregnant womens who consult a doctor at least once increases with the level of education. Less educated women less often demand treatment because they lack financial means or are less familiarized with the health system. As the level of pregnant women increases, the more they enter the medical coverage and the more their demand for healthcare is directed towards the medical units. Beninguisse [17] shows that the use of obstetric services by pregnant young women is considered as a function of their perceptions, beliefs and knowledge in the field of obstetrics, their financial resources and the accessibility of the medical units. Also, [18] find that the use of health services depends on social institutions such as habits, solidarity networks, perceptions or symbolic image of pregnancy and childbirth, degree of openness to modernity, and the economic conditions in which the women live. Existing studies on the determinants of the use of maternal health services in Cameroon are limited by the fact that they consider all modern health services as homogenous. However, the perception that a pregnant woman has of a district public hospital is not necessarily the same as that she has of the denominational or private district hospital while in both cases, the hospitals are modern health services. For example, an anxious mother will be able to travel a long distance to treat her child in a private health establishment or traditional midwife in which she has confidence but will not go the few kilometres separating her from the nearest public hospital because she believes that the latter will not be able to serve her properly [19]. This study aims at correcting this limit by seeking the determinants of the choice of healthcare of pregnant women taking into account the specificities of the health services.

The main objective of this study is to identify the determinants of the choice of health services of women in Cameroon. Its main contribution is that it identifies the determinants of the choice of treatment of pregnant women taking into consideration modern maternal health services and traditional ones.

The significance of this study is two fold. Firstly, maternal health is a millennium development objective with the target at 350 deaths per 100.000 live births according to the Growth and Employment Strategy Paper (GESP) [20]. In its GESP, the government in order to achieve this goal provides free treated mosquito nets for pregnant women and a reduction of obstetric costs. The success of this strategy primarily depends on the identification of the determinants of the use of maternal health services. Secondly, in view of reaping the benefits of the demographic transition, particularly the demographic dividend which is sought in the majority of Sub-Saharan African countries and Cameroon in particular, it is important to reinforce mother and child health by reducing maternal mortality. The demographic transition is a change in the demographic trends of the population of a country that results in low fertility and mortality rates. The expected benefit of the demographic transition is the demographic dividend, i.e. the acceleration of economic growth because of an increase in the working population and a fall in the dependent population.

The rest of the paper is organized as follows. Section The state of maternal health services in Cameroon presents the state of the use of maternal health services in Cameroon. Section Methods presents the methodology. Section Results and discussion discusses the results and section Conclusion concludes.

\section{The state of maternal health services in Cameroon}

The question of the access to maternal health services in the Cameroonian context is a major concern for the attainment of the Millennium Development Objectives and the evaluation of public policies of maternal health put in place by the government within the framework of its sectoral health strategy (SSS). In fact, the success of the public policies of maternal health requires the identification of the factors which explain the demand for maternal health services. In Cameroon level of underutilisation of maternal health services increased recently.

In fact, births in medical establishments remain low (43\%) in 2006 with differences between the poor (88\%) and non poor $(29,5 \%)$ and between the various areas $(11,1 \%$ in the North against $69,9 \%$ in the littoral) and between urban $(72,4 \%)$ and rural areas $(21,6 \%)$. The proportion of childbirth assisted by qualified health personnel fell between 2004 and 2006. At the national level, it passed from $61,8 \%$ in 2004 to $58,9 \%$ in 2006 [21]. The immediate consequence of this low recourse to health services is the rise of maternal mortality which passed from 430 to 669 deaths per 100000 births for the period 1998-2004 to 782 deaths in 2011. These deaths are closely linked to the frequency of visits to health establishments during pregnancy and at childbirth [21]. The health services received by a mother during pregnancy, at child birth and immediately after are not only very important for her survival and welfare but also 
for that of the child. In Cameroon, a real competition occurs for the supply of medical services. In fact, the resort to modern medicine is in strong competition with self medication (modern or traditional) and because of the absence of health services, their use is mainly controlled by patients (it reflects individual choices and decisions) and not by health professionals who have only a marginal control on the demand for services and treatment choices of their patients [22]. To be efficient, prenatal care must begin at an early stage of the pregnancy and continue regularly until childbirth. The World Health Organization (WHO) recommends at least four antenatal visits, the first in the third month of pregnancy with regular intervals throughout the pregnancy. Among the women having had a live birth during five years preceding the survey, $62 \%$ had at least the recommended four prenatal visits and this proportion is higher in urban $(77 \%)$ than in rural areas (50 \%). Concerning child delivery, among the deliveries which occurred during the five years preceding the survey, approximately three fifths occurred in a health establishment (61\%). In $37 \%$ of the cases, the women have delivered at home. Moreover, women of the rural areas (54 \%) deliver more frequently at home than those of the urban areas (14\%) [21].

\section{Methods}

The methodology is divided into the theoretical framework, the specification of the econometric model and the justification of the choice of the variables.

\section{Theoretical framework}

The theoretical framework is based on discrete choice models following the examples of [23, 24]. Discrete choice models are derived from the hypothesis that the choice of the individual follows a maximisation behaviour of the random utility [25, 26]. Formally, the utility $U_{i j}$ that the patient $i$ associates to each form of treatment $j$ is given by:

$$
U_{i j}=\beta_{0 j}+\beta_{1 j} X_{i}+\beta_{2 j} Q_{j}+\beta_{3 j} Y_{i}+\beta_{4 j} P_{j}+\varepsilon_{i j}
$$

The coefficients $\beta$ are attached to the indices $j$ showing that the effects of the explanatory variables can vary according to the treatment route (public, private denominational, private profit seeking and traditional midwives). $X_{i}$ is the characteristics of the pregnant woman. $Q_{j}$ is the characteristics of the choice of treatment. $\varepsilon_{i j}$ is the random error term which aims at capturing the unobserved determinants of the utility of the pregnant woman $i$ who chose the treatment $j . Y_{i}$ is the income of pregnant woman $i . P_{i j}$ the total cost of healthcare supported by the pregnant woman $i$ who chooses the treatment $j$. The preceding equation can be summarised by:

$$
\begin{aligned}
& U_{i j}=V_{i j}+\varepsilon_{i j} \\
& \text { With } V_{i j}=\beta_{0 j}+\beta_{1 j} X_{i}+\beta_{2 j} Q_{j}+\beta_{3 j} Y_{i}+\beta_{4 j} P_{j}
\end{aligned}
$$

The probability of selecting treatment route $j$ is equal to the probability that the utility given the pregnant woman by the supplier is higher than the utility associated with all the other routes.

That is to say: $P_{i j}=\operatorname{Pr}\left(U_{i j}>U_{i k}\right), \forall j \neq k$

$$
P_{i j}=\operatorname{Pr}\left(\varepsilon_{i k}-\varepsilon_{i j}>V_{i j}-V_{i k}\right), \forall j \neq k
$$

The calculation of the probability of Eq. (4) depends on the chosen distribution of the error term.

\section{Econometric specification}

The econometric specification depends on the hypotheses made with regard to the distribution of the error term of the probability of Eq. (4). Gertler et al. [23] develop a random utility model in which the demand for medical care is modeled as the decision to seek care and, conditional on that, the decision of which provider to use. The corresponding econometric specification is the nested multinomial logit model, which relaxes the independence of non relevant alternatives (IIA) assumption [27]. The use of a nested logit approach implies that choices can be organized into a meaningful nesting structure. Consider that the J alternatives can be classified in two groups as shown in the Fig. 1.

The expectant woman chooses between traditional and modern services and makes a final choice from the different alternatives in the group chosen. The probability that a pregnant woman choses a service $j$ given that she has chosen to resort to modern health services is given by the equation:

$$
\operatorname{Prob}\left(Y_{i}=j / M\right)=\frac{\exp \left(\beta_{j}^{\prime} z_{i}\right)}{\sum_{k}^{3} \exp \left(\beta_{j}^{\prime} z_{i}\right)}
$$

Also, the probability of choosing traditional health services over modern ones becomes:

$$
\begin{aligned}
\operatorname{Prob}\left(Y_{i}=0\right) & =\frac{\exp \left(\beta_{o}^{\prime} z_{i o}\right)}{\exp \left(\beta_{o}^{\prime} z_{i o}\right)+\exp \left(\lambda . I_{i}\right)}, \text { with } I_{i} \\
& =\ln \left(\sum_{k}^{3} \exp \left(\beta_{j}^{\prime} z_{i}\right)\right)
\end{aligned}
$$

In this formulation, the vector $\mathrm{z}_{\mathrm{io}}$ corresponds to a set of variables that affect the decision of the woman to resort to traditional or modern health services. The term $I_{i}$ 


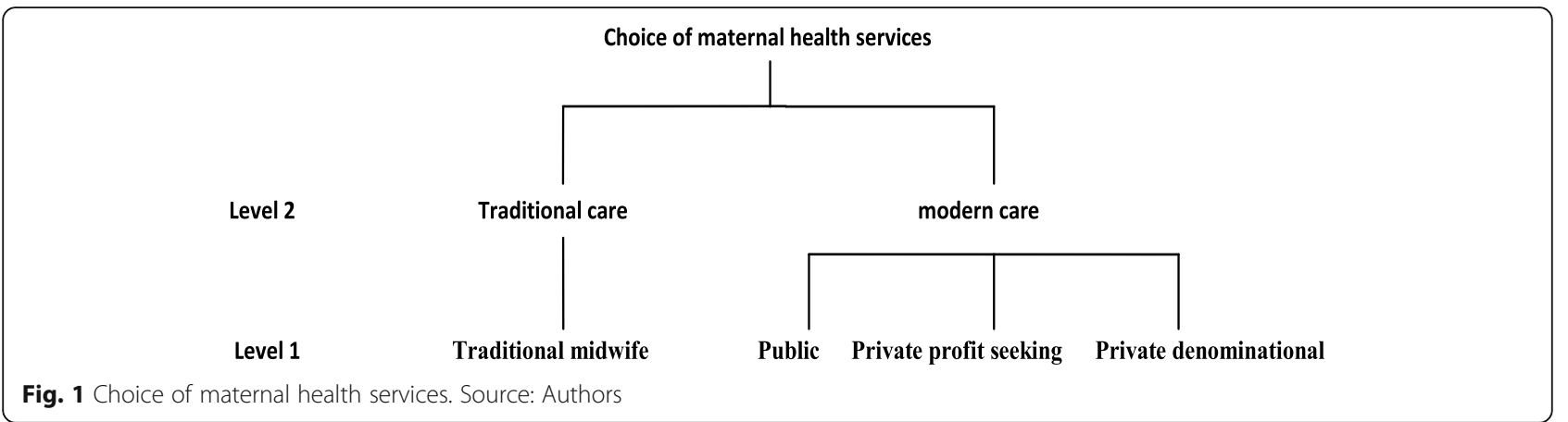

represents the inclusive value that shows the correlation between the choices of the modern health services subgroup. When the parameter $\lambda$ is different from 1 , the nested multinomial logit model drops the IIA hypothesis between the different choices of the decision tree. However, the IIA hypothesis is maintained between choices belonging to the same group. The probability of choosing a modern health service is thus given by:

$$
\operatorname{Prob}\left(Y_{i}=j\right)=\operatorname{Prob}\left(Y_{i}=j / M\right) \cdot\left(1-\operatorname{Prob}\left(Y_{i}=0\right)\right)
$$

\section{Choice of variables}

In the empirical literature, the identification of the determinants of the demand for health services by pregnant women takes into consideration several variables. The treatment options are presented in four alternatives: public services, private denominational services, private profit seeking services and traditional midwives. The recourse to public services represents the set of the public health structures. The recourse to private denominational services considers all the denominational private health structures. The recourse to private profit seeking services considers all the private profit seeking services. The traditional midwives takes into consideration the case where pregnant women consult traditional midwives who use grasses and barks of trees. Public services, private missionary institutions and private profit making organisations make up the modern maternal health services while traditional midwives make up the traditional health services. Several independent variables are used to explain the choice of treatment. These variables are explained below. The cost of using the services of health personnel is a factor which can guide the choice to consult a medical personnel or not in case of disease. In fact, when the cost of healthcare increases and the patient does not have the necessary means, she can resort to other alternatives which she finds at her reach or decide not to consult at all [28]. The cost of the healthcare represents the total expenditure on consultation, clinical tests, treatment, drugs and hospitalisation. The household income is one of the significant determinants of the demand of healthcare in a health system insofar as it can increase the probability of using a modern healthcare service. Health is priceless and the lack of a reasonable income cannot deprive a household of quality health services to protect its members. Income is measured in this study by the economic level: very poor, poor, averagely rich and very rich [29].

The perception which the pregnant woman or the members of her household have on the complication of her pregnancy is one of the factors that push pregnant women to demand health services. Women use a healthcare service only when they find that the pregnancy is at risk. If it is not at risk, the woman waits or practices alternative solutions $[6,28]$. Medical insurance can also explain the demand for health services because takes care of the costs of treating the insured woman. When one subscribes to insurance, or when we adhere to a mutual health insurance company, we tend to seek treatment in the event of disease near a health professional since we have the assurance that the costs of treatment are taken care of. The variable health insurance covers the insured women and members the mutual health insurance companies. Age has an impact on the choice of medical structures, the older a person is, the greater the probability that he chooses a modern health structure [30, 31]. It is also noticed that the educational level of the mother can be a determinant of the choice of the healthcare service insofar as when one is educated, one is supposed have more information on the importance of visiting a healthcare establishment or consulting a health personnel in case of disease than a person who is less educated [16, 32]. The size of the household is retained because it can influence the decision to seek for care or not. In fact, when a household is large and income is not sufficient, in case of disease, a choice is made between seeking for treatment and providing for other needs of the household. This is not the case when the size of the household is small [33]. Religion affects the attitude of women vis-a-vis pregnancy and modern healthcare. Some religions have a positive impact [34]; 
while others have a negative impact on the demand for healthcare [35]. There is a relationship between the quality of care and the demand for health services, bad quality reduces the demand for healthcare [36]. The variable quality of care is measured by satisfaction. A sick pregnant woman is satisfied with a provider of healthcare if she is cured by this provider. Transportation cost is not only an additional cost to the cost of healthcare but also an indicator of the proximity of health services. In this study transportation cost reflects the proximity of services and is related to the demand for healthcare [37]. Those who reside in urban environments are closer to healthcare services than those who reside in rural areas [29]. The variables retained from the empirical literature are: the cost of healthcare, the economic level of the household, complications of the pregnancy, health insurance, age, the level of education of the pregnant woman, the size of the household, religion, the quality of the healthcare services, the cost of transportation and place of residence.

\section{Study data}

The data used in this study is from the Demographic Health Survey (DHS) carried out in Cameroon in 2011. This survey is stratified into three main categories: the "Yaoundé/Douala" stratum, the "small towns" stratum and the "rural" stratum. The sampling is done at two levels. At the first level, the zones of sampling (ZS) are drawn with probabilities proportional to the number of households listed in the zones. At the second level, the households are drawn using lists written after an exhaustive enumeration of each ZS. Weighting coefficients are assigned to ensure the auto-weighting of the sample within each stratum. In 2011, the sample consisted of 14214 households, 15852 women aged 15-49 years and 7525 men aged 15-59 years. The survey on maternal health only considers women who requested a follow-up of their pregnancy for their most recent live birth that occurred in the five years preceding the survey. $85 \%$ of women benefit from a follow-up of their pregnancy. Also, the response rate to interviews for these women is $97 \%$. The DHS carried out in Cameroon in 2011 has information on the person consulted during the pregnancy, the possession of a notebook of antenatal consultations, the duration from the pregnancy to the first consultation, the number of antenatal and postnatal visits, the taking of anti tetanus vaccine and of anti malaria drugs during the pregnancy, the place of childbirth and assistance with childbirth. Table 1 gives the means and standard deviations of the explanatory variables.

\section{Results and discussion}

Table 2 gives the results of the Nested Multinomial Logit regression. Estimates in Table 2 reveal several lessons.
The level of education of the woman has a significant effect on the choice of the type of service. Uneducated women or women having received only a primary education prefer visiting the traditional midwives to modern healthcare services. In other studies [8-13], a similar result is found. The relationship between the access to a remunerated employment for the pregnant women and the use of the modern healthcare services is positive. This result confirms that the decision to choose modern healthcare services to the detriment of the traditional midwives can be explained by the nature of the employment of the pregnant women. This result is confirmed by [11]. However, employment may not necessarily be associated with greater use of maternity care if: (i) women have little control over their earnings; (ii) employment is largely poverty-induced and reflects resource constraints and (iii) employment is seasonal and poorly remunerated [11, 34, 38].

The women of Islamic and animist religions are those who prefer the services of the traditional midwives to those of modern medical institutions. A similar result is obtained by [35]. The effect of culture can partially explain this result. In fact, in the North and Far-North regions which are mainly Moslem, the decision to resort to maternal healthcare services does not belong to the pregnant woman but to her husband. In addition, the traditional midwives are closer to the pregnant women than modern services of healthcare which are sometimes too far. In the case of the animist religion, cultural practices also favour the choice of the traditional midwives to modern services of maternal healthcare. Reinforcing the recourse to modern services of maternal healthcare in a context strongly influenced by cultural values inevitably passes through the implication of the traditional midwife to the processes of modern of healthcare [39]. However, the relationship between religion and the demand for modern maternal health services could also be explained by differences in living standards between the different religious groups and not religion. It is possible that women belonging to a particular religious group are poorer and thus have a lower demand for modern health services [40]. In the case of Cameroon, the high rate of poverty in Moslem regions could explain the negative relationship between the Moslem regions and the low demand for modern health services by women from these regions. The women whose last pregnancy was complicated tend to visit modern medical institutions than request the services of traditional midwives. The study by Magadi et al. [6] holds that complications in the first pregnancies have a positive effect on the demand for modern health services. In the same manner, a large size of the household seems to be unfavourable to the use of modern medical institutions by the pregnant women. Furthermore, the married pregnant woman uses 
Table 1 Means and Standard deviations of explanatory variables

\begin{tabular}{|c|c|c|}
\hline Variables & Mean & Standard deviation \\
\hline \multicolumn{3}{|l|}{ AGE } \\
\hline $15-25$ years & 0,3280 & 0,4672 \\
\hline $26-29$ years & 0,4413 & 0,4965 \\
\hline $30-49$ years & 0,2302 & 0,4209 \\
\hline \multicolumn{3}{|l|}{ Level of education } \\
\hline No education & 0,2968 & 0,4568 \\
\hline Primary education & 0,4297 & 0,4950 \\
\hline Secondary & 0,2524 & 0,4344 \\
\hline Higher & 0,0211 & 0,1436 \\
\hline \multicolumn{3}{|l|}{ Occupation } \\
\hline Paid employment & 0,7704 & 0,4205 \\
\hline Employment not remunerated & 0,2296 & 0,4205 \\
\hline \multicolumn{3}{|l|}{ Area of Residence } \\
\hline Rural & 0,5554 & 0,4969 \\
\hline Urbain & 0,4446 & 0,4969 \\
\hline \multicolumn{3}{|l|}{ Religion } \\
\hline Catholic & 0,3439 & 0,4750 \\
\hline Protestant & 0,3380 & 0,4730 \\
\hline Moslem & 0,2344 & 0,4236 \\
\hline Animist & 0,0302 & 0,1711 \\
\hline Other Christian & 0,0228 & 0,1492 \\
\hline \multicolumn{3}{|l|}{ Matrimonial status } \\
\hline Single & 0,0374 & 0,0189 \\
\hline Married & 0,7172 & 0,4503 \\
\hline Cohabitation & 0,1342 & 0,3409 \\
\hline Widow & 0,0552 & 0,2282 \\
\hline divorced & 0,0374 & 0,1897 \\
\hline \multicolumn{3}{|l|}{ Size of household } \\
\hline $1-4$ & 0,2338 & 0,4232 \\
\hline $5-10$ & 0,4811 & 0,4933 \\
\hline 11 and more & 0,3297 & 0,3360 \\
\hline \multicolumn{3}{|l|}{ State of previous pregnancy } \\
\hline Complicated & 0,03 & 0,1784 \\
\hline Noncomplicated & 0,97 & 0,1778 \\
\hline \multicolumn{3}{|l|}{ Index of wealth } \\
\hline Very poor & 0,2111 & 0,4080 \\
\hline Poor & 0,2392 & 0,4266 \\
\hline Average & 0,2212 & 0,4150 \\
\hline Rich & 0,1860 & 0,3891 \\
\hline Very rich & 0,1400 & 0,3500 \\
\hline \multicolumn{3}{|l|}{ Cost of care } \\
\hline $100-1000$ & 0,2780 & 0,1323 \\
\hline $1005-10000$ & 0,3830 & 0,0909 \\
\hline 10005 and more & 0,3619 & 0,0436 \\
\hline
\end{tabular}

Table 1 Means and Standard deviations of explanatory variables (Continued)

\begin{tabular}{lll}
\hline Cost of transport & & \\
$0-100$ & 0,2411 & 0,4906 \\
$150-400$ & 0,4170 & 0,2654 \\
500 and more & 0,3312 & 0,5699 \\
Insurance & & \\
Ensured & 0,0298 & 0,4122 \\
Not assured & 0,9702 & 0,7701 \\
Quality of the care & & \\
Bad & 0,5841 & 0,2278 \\
Good & 0,4159 & 0,4945 \\
\hline
\end{tabular}

Source: Author using data from [21]

modern maternal services more than the single woman. This result is in line with those of [11]. The positive influence of marital status may reflect the stigmatization single expectant mothers go through since childbearing, in most communities, is perceived as an act reserved for those who are married [41]. In addition when a pregnant woman is poor, she prefers the services of the traditional midwife to those of the modern health services. Similar studies $[8,11,42]$ also confirm the negative effect of poverty on the demand for modern health services.

Concerning the type of modern health services chosen by pregnant women, many lessons can be drawn. The cost of healthcare discourages the recourse to modern services of healthcare. In fact, when the costs of healthcare increase in modern medical institutions (public, Private denominational, Private profit seeking), the women prefer to use the services of traditional housewives. The costs of transport also constitute a barrier to the use of modern services of healthcare by pregnant women. Other studies $[8,43]$ agree that the cost of maternal health services and transportation costs are financial obstacles faced by pregnant women who decide to use modern maternal health services. Also, maternal health units that offer services covered by a health insurance attract more pregnant women. The quality of services is also a factor that affects the choice of a healthcare provider. Our results show that the positive effect of the quality of healthcare on the choice of healthcare provider is higher for private profit seeking and denominational hospitals. A similar study [44] confirms that pregnant women use the services of a given provider when the perceived quality of treatment meets expected standards in past visits. We also find a negative relationship between rural maternal health service providers and the use of these services by pregnant women. This negative relationship can be explained by physical 
Table 2 Results of the estimates of the nested multinomial logit model (marginal effects)

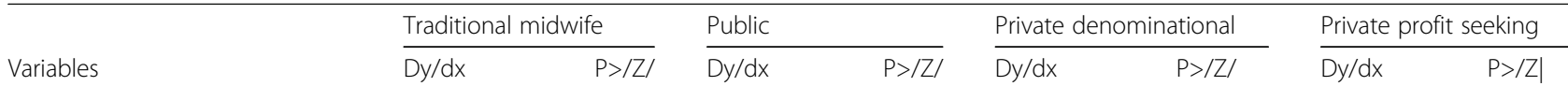

Choice of modern healthcare services (level 2)

Age 15-25 years

26-30 years

31-49 years

Level education

No education

Primary education

Secondary

Higher

Occupation

Remunerated employment
Employment not remunerated

Religion

Catholic

Protestant

Moslem

Animist

Other Christian religions

State of last pregnancy

$$
\text { Complicated }
$$

Non complicated

Matrimonial statute

Single
Married
Cohabitation
Widowed/Divorced
Size of the household

$$
1-4
$$

5-10

11 and more

Index of wealth

Very poor

Poor

Average

Rich

Very rich

ype of moder

Cost care (FCFA)

5000-30000

30005-100000

100005 and more ref.

ref.

$-0,052229$

0,978

$-0,077863^{* *}$

0,034

$0,716561^{* * *} \quad 0,002$

$0,277552^{*} \quad 0,073$

$-0,8183958^{* *} \quad 0,016$

ref.

ref.

$-0,1025579^{* *} \quad 0.033$

ref.

ref.

$-0,1585394 \quad 0,446$

$-0,446 \quad 0,210$

$0,431396^{*} \quad 0,000$

$0,394046 * \quad 0,903$

ref.

ref.

$-0,4353877^{* *} \quad 0.032$

ref.

ref.

$0,7689184^{* * *} \quad 0,001$

$-0,4279708^{* *} \quad 0,010$

$-0,1742246 \quad 0,302$

Ref.

ref.

ref.

$0,4580059^{* *}$

ref.

$0,527099^{* * *}$

0.001

$0,430192^{* * *}$

0,000

$0,285039^{* * *}$

0,000

$-0,458281 * * *$

0.006

$-0,380440^{* *}$

ref.

ref.

ref.

$\mathrm{P}>/ \mathrm{Zl}$

$P>/ Z \mid$ 
Table 2 Results of the estimates of the nested multinomial logit model (marginal effects) (Continued)

\begin{tabular}{|c|c|c|c|c|c|c|c|c|}
\hline \multicolumn{9}{|c|}{ Cost of transport (FCFA) } \\
\hline $0-100$ & - & - & ref. & ref. & ref. & ref. & ref. & ref. \\
\hline $150-400$ & - & - & $-0,70673^{* *}$ & 0,024 & $-0,50480$ & 0,711 & 0,01550 & 0,260 \\
\hline 500 and more & - & - & $-0,781356^{* *}$ & 0,032 & $-0,56054^{*}$ & 0,093 & $0,5403^{* * *}$ & 0,000 \\
\hline \multicolumn{9}{|l|}{ Insurance } \\
\hline Ensured & - & - & $0,455742^{* * *}$ & 0,001 & $0,8821^{* * *}$ & 0.000 & $0,7683^{* * *}$ & 0,000 \\
\hline Not assured & - & - & ref. & ref. & ref. & ref. & ref. & ref. \\
\hline \multicolumn{9}{|l|}{ Quality of the care } \\
\hline Good & - & - & $0,51071^{* *}$ & 0,032 & $0,570^{* * *}$ & 0,000 & $0,6287^{*}$ & 0,0820 \\
\hline Bad & - & & ref. & ref. & ref. & ref. & ref. & ref. \\
\hline Place of Residence & & - & & & & & & \\
\hline Rural & - & - & $-0,304343^{* *}$ & 0,032 & $-0,1095^{*}$ & 0,079 & $-0,0023$ & 0.540 \\
\hline Urban & - & - & ref. & ref. & ref. & ref. & ref. & ref. \\
\hline Inclusive value $\lambda$ & $4,465^{* * *}$ & 0.000 & & & & & & \\
\hline
\end{tabular}

Number of individuals = 4485; Wald chi2 $(124)=2837.126$; Log Prob $>$ chi2 $=0.0000$ likelihood $=-5366.5916$

Source: Author using data from [21]. Note: indication of level of significance: ${ }^{* * *} p \prec 0.01,{ }^{* *} p \prec 0.05,{ }^{*} p \prec 0.1$ ref.: reference class $=$ traditional midwife, for level 1

obstacles, particularly transport faced by rural women who are generally poorer $[8,11]$.

However, this study is limited to the factors explaining the choice of maternal healthcare services by pregnant women. Specifically, the study does not investigate the determinants of the volume of maternal healthcare services consumed once the provider has been chosen. Meanwhile, after choosing the maternal healthcare service provider by the pregnant women, it is important to analyze the factors that determine the quantity of the maternal healthcare services they consume. As such, uture studies would aim at identifying the factors that determine the quantity of healthcare services consumed once the provider has been chosen. This is important as access to maternal healthcare services is not limited only to the choice of the healthcare service provider.

\section{Conclusion}

This study seeks to identify the determinants of the treatment choices of pregnant women in Cameroon. Among the significant results of the empirical analysis, we can retain that the absence of education or primary education are factors which reduce the demand for modern services of maternal health on the one hand and on the other hand favour the demand of the services of traditional midwives on the other hand. Moreover, the absence of a paid employment for the woman, the large size of the household, Islamic or animist religions, the poor quality of healthcare services in modern healthcare centres, poverty, high costs of healthcare and transport are constraints which push pregnant women to prefer the services of traditional midwives to those of the modern services of maternal health. From the results of this study, three important lessons are retained: firstly, the education of women increases their capacity to use modern maternal healthcare services. The low observed school attendance rate girls therefore partly explains the high maternal mortality rate observed in certain regions like the North and Extreme-North regions of the country. Secondly, salaried employment enforces the economic power of women, increasing their capacity to use modern than traditional maternal healthcare services. Therefore, maternal mortality can also be reduced through the economic empowerment of women. Finally, the existence of a health insurance scheme increases the use of modern maternal healthcare services. In fact, healthcare services directly financed by pregnant women or their families can be a factor of exclusion especially for poor women. After choosing the maternal healthcare service provider by the pregnant women, it is important to analyze the factors that determine the quantity of the maternal healthcare services they consume. As such, future studies would aim at identifying the factors that determine the quantity of healthcare services consumed once the provider has been chosen.

\section{Authors' contributions}

The first author contributed to the conception of this article, to the analysis and the interpretation of the results and has been involved in drafting the manuscript. The second author contributed to the interpretation of the results and has been involved in drafting the manuscript. All authors made substantial contributions and participated in drafting and writing the article. Both authors read and approved the final manuscript.

Competing interests

The authors declare that they have no competing interests. 


\section{Ethics approval and consent to participate}

This study was approved by the National Committee of Ethic, Cameroon. The data used in this work are from the demographic and health survey organised in Cameroonm in 2011 by the National Institiute of Statistics. The protocol of this survey is based on the anonymous-link protocol developed by the Demographic and Health Surveys (DHS) programme. All datas are strictly anonymous.

Received: 7 May 2016 Accepted: 14 October 2016

Published online: 24 October 2016

\section{References}

1. Schultz TP. Investment in capital human. A E R. 1961;51(1):1-17.

2. Grossman M. On the concept of health capital and the demand for health. J Pol Eco. 1972;80:223-55.

3. Zweifel P, Breyer F, Kifmann M. Health Economics. Second Edition. New York: Springer; 2009.

4. Lancaster K. A new approach to consumer theory. J Pol Eco. 1966;74:132-57.

5. Rwenge M. La qualité des soins prénatals selon la perspective des clients au Cameroun dans les districts de santé de Nkongsamba, Bafang et Mfou. Africa Pop Stud. 2007;22:23-46.

6. Magadi MA, Madise NJ, Rodrigues RN. Frequency of timing of antenatal care in Kenya: Explaining the variations between women of different communities. Soc Sci Med. 2000;51:551-61.

7. Magadi MA, Zulu EM, Brockerhoff M. The inequality of maternal health care in urban sub-Saharan Africa in the 1990s. Pop Stud. 2003:57:347-66.

8. Sepehri A, Sarma S, Simpson W, Moshiri S. How important are individual, household and commune characteristics in explaining utilization of maternal health services in Vietnam? Soc Sci Med. 2008;67:1009-17.

9. Shrestha G. Factors related to utilization of antenatal care in Nepal: a generalized linear approach. J Kathmandu Med Coll. 2013;2:69-74.

10. Beeckman K, Louchx F, Putman K. Determinants of the number of antenatal visits in a metropolitan region. BMC Public Health. 2010;10:527-36.

11. Guliani H, Sepehri A, Serieux J. Determinants of prenatal care use: evidence from 32 low-income countries across Asia, sub-Saharan Africa and Latin America. Health Policy Plann. 2014;29:589-602

12. Haddad G S, DeJong J, Terreri N, Clara M, et al. Patterns and determinants of antenatal care utilization: analysis of national survey data in seven countdown countries. J Global Health. 2016;6(1). doi:10.7189/jogh.06.010404.

13. Celik $Y$, Hotchkiss DR. The socioeconomic determinants of maternal health care utilization in Turkey. Soc Sci Med. 2000;50:1797-806.

14. Saxena D, Vangani R, Mavalankar DV, Thomsen S. Inequity in maternal health care service utilization in Gujarat: Analyses of district-level health survey data. Global Health Act. 2013;6:1-9.

15. Houweling TAJ, Ronsmans C, Campbell OMR, Kunst AE. Huge-poor-rich inequalities in maternity care: an international comparative study of maternity and child care in developing countries. Bull WHO. 2007;85:745-54

16. Commeyras C, Ndo JR. Etude de l'accessibilité et des déterminants de recours aux soins et aux médicaments pour les populations du Cameroun. 1999. Ministère dela Santé du Cameroun.

17. Beninguisse $\mathrm{G}$. Entre tradition et modernité. Fondements sociaux de la prise en charge de la grossesse et de l'accouchement au Cameroun. Yaounde: L'Harmattan \& Academie; 2003.

18. Rwenge MJR, Nguemaleu THB. Facteurs Sociaux de l'utilisation des Services de soins Obstétricaux Parmi les Adolescentes Camerounaises. African J Reprod Health. 2011;15(3):81-92.

19. Balique H. Rapport d'étape de la consultation d'appui à la réforme hospitalière. Cameroun: Ministère de la santé publique; 2003.

20. DSCE. Document de Stratégie pour la Croissance et l'Emploi. Cameroun: Ministry of Economic, planning and Regional Development; 2009.

21. EDS-MICS. $4^{\text {ème }}$ Enquête Démographique et de Santé et à Indicateurs Multiples EDS-MICS. Cameroun: Institut National de la Statistique; 2011.

22. Ntembe A. User Charges and Health Care Provider Choice in Cameroon. Intern Rev Business Research Papers. 2009;5(6):33-49.

23. Gertler P, Locay L, Sanderson W. Are user fees regressive? The welfare implications of health care financing proposals in Peru". J Econometr. 1987;36:67-8.

24. Akin JS, Griffin CC, Guilkey DK, Popkin BM. The demand for primary health care services in the Bicol Region of the Philippines. Econ Dev Cult Change. 1986;34(4):755-82
25. Acton JP. Nonmonetary factors in the demand for 19 services. Some empirical evidence. J Pol Eco. 1975:83:595-616.

26. Christianson JB. Evaluating Location for Outpatient Medical Care Facilities. Land Eco. 1976:52(3):299-313.

27. Jones A. Health econometric. 1998. www.york.ac.uc/che/pdf.op31.pdf.

28. Sauerborn R, Nougtar A, Latimer E. The elasticity of demand for health care in Burfina Fasso: difference across age and income group. Health Policy Plann. 1994;9(2):185-92.

29. Duchesne D. Evaluation de la fonction de la demande de soins de santé en Tanzanie. Centre de recherche et développement en économique (C.R.D.E). 1998. Université de Montréal.

30. Elo IT. Utilization of maternal health-care services in Peru: the role of women's education. Health Trans Rev. 1992;2:49-69.

31. Fosu GB. Childhood morbidity and health services utilization: cross-national comparisons of user-related factors from DHS data. Soc Sci Med. 1994;38:1209-20.

32. Becker S, Peters DH, Gray RH, Gultiano C, Black RE. The determinants of use of maternal and child health services in Metro Cebu, the Philippines. Health Trans Rev. 1993;3:77-89.

33. Wong L, Popkin BM, Guilkey DK, Akin JS. Accessibility, quality of care and prenatal care use in the Philippines. Soc Sci Med. 1987;24:927-44.

34. Addai FK. Health sector reforms in developing countries and implications for reproductive health priority setting. Stud Fam Plann. 2000;28(2):143-50.

35. Raghupathy S. Education and the use of maternal health care in Thailand. Soc Sci Med. 1996;43:459-71.

36. Mariko M. Quality of care and the demand for health services in Bamako, Mali: the specific roles of structural, process, and outcome components. Soc Sci Med. 2003;56:1183-96.

37. Stock R. Distance and utilization of health facilities in rural Nigeria. Soc Sci Med. 1983;17:563-70.

38. Gabrysch S, Campbell O. Still too far to walk: literature review of the determinants of delivery service use. BMC Pregnancy Child Birth. 2009:9:1-18.

39. Nguenda. ASB. Téléphone mobile et accès aux soins de santé maternelle infantile au Cameroun. Revue économique et sociale africaine, REVUE-CEDRES. $2014, N^{\circ} 58$

40. Sirpe $\mathrm{G}$. Les déterminants du recours aux soins de santé prénataux au Burkina Faso. Mondes en Dév. 2011;1:153.

41. Duong D, Binns C, Lee A. Utilization of delivery services at the primary health care level in rural Vietnam. Soc Sci Med. 2004;59:2585-95.

42. Say L, Raine R. A systematic review of inequalities in the use of maternal health care in developing countries: examining the scale of the problem and the importance of context. Bull W HO. 2007;85:812-19.

43. Borghi J, Ensor T, Somanathan A, Lissner C, Mills A. Maternal survival 4: mobilizing financial resources for maternal health. Lancet. 2006;368:1457-65.

44. Ndyomugyenyi R, Neema S, Magnussen P. The use of formal and informal services for antenatal care and malaria treatment in rural Uganda. Health Policy Plann. 1998;13:94-102.

\section{Submit your manuscript to a SpringerOpen ${ }^{\circ}$ journal and benefit from:}

- Convenient online submission

- Rigorous peer review

- Immediate publication on acceptance

- Open access: articles freely available online

- High visibility within the field

- Retaining the copyright to your article

Submit your next manuscript at $>$ springeropen.com 